\title{
LUIS PÉREZ EL GALLEGO: HISTORIA, SÁTIRA, BIOPOLÍTICA
}

\author{
Enrique García Santo-Tomás \\ University of Michigan, Ann Arbor \\ 500 S State St, Ann Arbor, Michigan 48109. USA \\ enriqueg@umich.edu
}

El presente trabajo amplía una línea de investigación y reflexión desarrollada en un reciente artículo en el cual examinaba la figura de Roque Guinart como un referente social invocado en la escena política española contemporánea, si bien algo alejado ya del modelo cervantino tras sus diferentes recreaciones en el tiempo. Con el título de «Recasting Roque: Cervantes's Bandits and the Politics of Drama», sostenía en dicho estudio que el encuentro de Don Quijote y Sancho con el célebre bandido (II, 60-61) abría en la novela un espacio semi-autónomo que no solo era geográfico - en la medida en que aislaba momentáneamente a sus protagonistas de un antes y un después narrativo- sino también político, pues en él se dirimían cuestiones capitales en torno a la representación novelesca y novelada del poder, de la violencia y de los posibles mecanismos de resistencia imaginados por Cervantes. Estos mecanismos respondían a una realidad local que entraba por primera vez en la ficción quijotesca, conectando con una serie de eventos recientes como habían sido, por ejemplo, las disputas entre Robuster de Vich y Alexandre d'Alentorn unos años antes ${ }^{1}$. Eran estos, además,

${ }^{1}$ Se trata, como es sabido, de Francisco Robuster y Sala, Obispo de Vich, y de Alexandre de Alentorn i de Botella, señor de Seró y diputado de la Generalitat. El 
unos episodios en los que el lector se topaba con el primer personaje histórico de la novela, Perot Oristá Rocaguinarda (1582-1635), cuyas hazañas se habían convertido ya en materia de leyenda en la España de los Austrias.Y era esta una materia que, añado ahora, ofrece todavía espacio para el análisis en la medida en que sigue siendo relevante: si la bibliografia existente se ha centrado en asuntos como el contexto histórico, el dilema moral propuesto por Cervantes ante el propio dilema del bandido o la amalgama de historia y ficción en las peripecias de estos forajidos, poco se ha escrito sobre la fortuna teatral del bandolero catalán. Las diferentes refundiciones y reescrituras en el tiempo han logrado reactivar un importante debate en torno a la representación y al papel de Cataluña en el destino imperial de la nación, como sostuve a través del análisis de la fascinante pieza de Antonio Coello y Pacheco titulada Roque Guinart (1874). Desde el retrato dramatizado de este nuevo Roque - un Roque brutal y sanguinario que desde su lejana periferia no contribuía sino a reforzar ante un público madrileño su propia centralidad social y política - sugerí que Coello y Pacheco intervenía de forma inequívoca en los debates en torno a la figura de Cervantes en el Madrid de la recién estrenada Restauración ${ }^{2}$. Con ello lograba también fijar un importante eslabón de esta cadena hermenéutica que ha llegado hasta nuestro propio presente, en un país con la fragmentación política y cultural como una de sus más visibles señas de identidad. Una fragmentación que, como resultado, ha generado debates de índole social, política y económica en los que la figura de Roque Guinart - ya como ladrón, ya como justiciero - ha vuelto a ser recuperada por políticos y periodistas de ideología varia ${ }^{3}$.

Por consiguiente, si algo nos enseña este contraste entre el ayer y el hoy, es que la figura del bandolero ha sido y sigue siendo un barómetro de gran fidelidad a la hora de registrar el nivel de descontento de una comunidad ante la amenaza de su propio resquebrajamiento. Roque Guinart ha encarnado esta inquietud durante los últimos cuatro siglos como pocos lo han hecho, conviviendo con toda una genealogía de

primero fue cadell, el segundo nyerro; ambos tuvieron un marcado protagonismo en los conflictos entre las villas y pueblos (generalmente del lado cadell) y la nobleza feudal (identificada con los nyerros).

${ }^{2}$ Para un reciente análisis sobre los debates decimonónicos en torno a Cervantes como icono cultural, ver Pérez Magallón, 2015.

${ }^{3}$ Ver, por ejemplo, López Díaz, 2015; Salas, 2015. 
bandoleros andaluces, madrileños o gallegos que igualmente ha trascendido lo real para instalarse con éxito en el terreno de la ficción, desde la novela al cante, desde el teatro a la televisión, desde la pintura al cine. Es ya sabido que algunos episodios convulsos de la ya de por sí convulsa historia de España, como fueron la Guerra de Sucesión (1702-1713) o la Guerra de la Independencia (1808-1818), dieron lugar a un marcado aumento del bandidaje en diversas regiones del territorio nacional, y con ello a la popularización de héroes locales sublimados desde un halo romántico que ha llegado hasta hoy día. Del bandolero andaluz, catalán y castellano existe ya bibliografia abundante, incluso centrada en el terreno de la ficción literaria, y por tanto no volveré a ellos ahora ${ }^{4}$. Poco se ha escrito, sin embargo, sobre el arquetipo del bandido gallego, acaso menos ruidoso que sus pares peninsulares, pero del que sin embargo tenemos algunos testimonios tan significativos como sintomáticos de un sentir muy particular que, como apuntaré en breve, resulta ineludible en cualquier discusión sobre espacio, identidad y memoria histórica. El presente trabajo busca colmar esta laguna crítica a través del examen de Luis Pérez el gallego (1629) de Calderón de la Barca, de importancia secundaria en el canon teatral áureo, pero que sin embargo logra enriquecer de forma más que notable nuestra comprensión de este fenómeno. La pieza calderoniana — pieza de juventud de un dramaturgo más idealista y rebelde que prudente y desengañado- conecta de múltiples formas con el bandolerismo catalán en la presentación de unos conflictos que van a ser más tarde recreados por dramaturgos de toda índole, tanto en España como en el extranjero. Desde el examen interno de su factura dramática hasta el análisis de sus reverberaciones diacrónicas, la pieza calderoniana me sirve para reflexionar, en última instancia, sobre aspectos que palpitan en cualquier representación contemporánea de los clásicos, a saber: el de identidad regional en su relación con el uso de la memoria, o el de la delicada tensión entre libre albedrío y las tecnologías de control emergentes en el siglo XVII, que han venido a ser parte esencial de ese concepto teórico de gran utilidad y al cual hemos venido a llamar biopolítica.

\footnotetext{
${ }^{4}$ Ver, por ejemplo, Reglá, 1968; García Cárcel, 1989. A modo de introducción, sigue siendo de gran utilidad Hobsbawm, 2000.
} 


\section{Calderón, territorio y ley}

El bandolero, como ha sido señalado ya en numerosas ocasiones, fue material de gran rendimiento dramático en los Siglos de Oro, hasta el punto de que se puede afirmar que no hubo ingenio áureo que no contribuyera a esta poliédrica semblanza con su propia aportación ${ }^{5}$. Álvaro Cubillo de Aragón escribió El bandolero de Flandes, Tirso de Molina hizo lo propio en piezas como El condenado por desconfiado, La ninfa del cielo o El bandolero, en ese retrato tan cercano a su Orden mercedaria de San Pedro Armengol. Calderón de la Barca construyó un fascinante personaje en La devoción de la cruz, mientras que LuisVélez de Guevara probó suerte con El niño Diablo; Francisco de Rojas Zorrilla llevó a las tablas El bandolero Solposto, Felipe Godínez añadió a esta tradición $O$ el fraile ha de ser ladrón o el ladrón ha de ser fraile, Agustín Moreto firmó San Franco de Sena y Juan Ruiz de Alarcón nos dejó la obra maestra El tejedor de Segovia. Incluso desde la escritura en colaboración, tres de los más grandes poetas de su tiempo como fueron Coello, Rojas y Vélez probaron fortuna con El catalán Serrallonga, inspirados en el personaje histórico de Juan Sala y Serrallonga, que murió ajusticiado en 1633.Y el propio Lope de Vega, autor de la comedia Las dos bandoleras, rindió tributo a la actualidad del momento con Roque Dinarte (1611-1618), pieza citada en el inventario de El peregrino en su patria pero que hasta la fecha se encuentra perdida.

Inspirada al parecer en un hecho histórico — según conjeturaron Juan Eugenio Hartzenbusch y más tarde Ángel Valbuena Briones ${ }^{6}$-, Luis Pérez el gallego es una pieza un tanto atípica en la producción calderoniana, empezando acaso por su desigual fortuna escénica. Se cree que fue estrenada el 21 de diciembre de 1629 por Antonio de Prado, aunque no fue impresa hasta $1652^{7}$. El texto se reprodujo varias veces más y contó con numerosas representaciones en las primeras cuatro décadas del siglo xviII. Motivado quizá por su tremenda popularidad, el militar y erudito Manuel de Anero Puente compuso una segunda parte también llamada Luis Pérez el gallego, estrenada en el Teatro del Príncipe el 16 de abril de $1717 .{ }^{8}$ En ella incluyó a personajes nuevos (Carlos V,

\footnotetext{
${ }^{5}$ Ver Parker, 1949; Jauralde Pou, 1991; Antonucci, 1995; Cardinale, 2009; Ledroit, 2009; García Gónzalez, 2012.

${ }^{6}$ Así lo ha indicado también, por ejemplo, Suárez Miramón, 2013, p. 211.

${ }^{7}$ Cruickshank, 2009, p. 78; Buezo, 2006, p. 123.

${ }^{8}$ Ver Andioc y Coulon, 1996, vol. II, p. 758.
} 
el duque de Alba, Barbarroja, moros...), situando la trama en 1535 en la toma de La Goleta, y con el bandolero portando el nombre falso de Álvaro Sarmiento. La comedia calderoniana fue reeditada y traducida en varios idiomas (al francés en 1822, 1841 y 1873, al inglés en 1853 y 1906, al alemán en 1891 y 1952, al ruso en 1961...), debido en parte a lo que Ángel Valbuena Briones vio como un «signo prerromántico»" muy cercano al popular Cyrano de Bergerac y que, sabemos ya, sirvió de inspiración en la semblanza del Carlos Moor de Los bandidos de Friedrich Schiller (1781). Sin embargo, hay algo también en la pieza de sesgo post-romántico que justificaría sus reencarnaciones desde la segunda mitad del xix, muchas de ellas provenientes del extranjero. Desde el ámbito calderoniano, la crítica más reciente se ha enfocado en la serie de situaciones enlazadas entre sí en torno a la vida de Luis Pérez, un gallego transformado en bandido a causa de lo que estudiosos como Ana Suárez Miramón y Nieves Pena Sueiro han visto como un concurso fatal de circunstancias. Su factura guarda mucha semejanza con la ya citada comedia El tejedor de Segovia, si bien con situaciones trufadas de peripecias y con varios desplazamientos geográficos que la dotan de un «dinamismo acelerado», según Ignacio Arellano ${ }^{10}$.

La trama de Luis Pérez el gallego, como es sabido, se inicia con la presentación del protagonista, quien vive armónicamente con su hermana Isabel en "las entrañas de una sierra» (p. 145) ${ }^{11}$ colindante con la comarca de Salvatierra (Pontevedra). A través de un mensaje que intercepta de su criado Pedro, Luis se entera de que ésta es cortejada por Juan Bautista, un rico vecino al que no tiene afecto alguno por su ascendencia judía y también por ser un cobarde («sospecho / que no hay valor en su pecho / para que tu esposo sea» [p. 145]). Luis, de hecho, amenaza con poner «a su casa fuego, / quitando a la Inquisición / ese trabajo») (p. 145). La calma rural queda definitivamente rota cuando llega, proveniente de Portugal, un antiguo amigo llamado Manuel Méndez, en busca de refugio seguro tras haber matado a quien iba a convertirse en esposo de

\footnotetext{
${ }^{9}$ Valbuena Briones, 1969, p. 142. Por su parte, Bergman, 2003, pp. 181-184, conecta a Luis Pérez con el tipo del valiente, identificando un sustrato entremesil debido a determinados rasgos de su conducta.

${ }^{10}$ Arellano, 2001, p. 96.

${ }^{11} \mathrm{Al}$ no estar numerados los versos, cito a partir de aquí por el número de página de la edición utilizada.
} 
su amante Juana, quien le acompaña ahora ${ }^{12}$. Luis le invita a esconderse en su quinta justo antes de que llegue otro conocido, un tal Alonso de Tordoya, que va huyendo a Portugal perseguido por el Corregidor de Salvatierra y sus alguaciles por haber matado a un rival amoroso en duelo. En otra muestra más de lealtad y generosidad, Luis se interpone entre uno y otros con el fin de dirimir justicia, con lo que el Regidor ordena que se le mate. El gallego se defiende dando muerte a uno de los oficiales y huyendo al bosque, donde se reúne con Alonso y con la pareja Manuel-Juana. Decide entonces cruzar el río con el primero de ellos a hombros — pues este no sabe nadar- y adentrarse en Portugal, mientras que Manuel y Juana marchan a su quinta, donde velarán por Isabel. Al otro lado del río andan de caza dos personajes nuevos, el Almirante de Portugal y su sobrina Leonor, quienes se encuentran primero con Pedro (que viene huyendo de su amo) y luego con Luis y Alonso, calados hasta los huesos tras haber cruzado el río. Se revela entonces que este último ha dado muerte a un tal don Diego de Alvarado, que resulta ser hermano de Leonor y sobrino del Almirante. Este, que le había garantizado protección antes de saber las causas de su destierro, le amnistía al estar en su territorio, pero le recuerda que no estará seguro en ningún otro lugar:

Todo el tiempo que estuvieres
en mi tierra, está guardada
tu persona; pero advierte
que al salir de ella, te aguarda
la muerte; que si ofrecí
defenderte hoy en mi casa,
en mi casa te defiendo;
pero no te di palabra
de guardarte en el ajena (p. 153).

La acción se traslada en la segunda Jornada a Sanlúcar de Barrameda durante los preparativos de la expedición marítima de la Armada invencible en 1588 «a las islas / del norte...» (p. 155) - hay referencias, por ejemplo, al duque de Medina Sidonia y al funcionamiento del ejército. Nos encontramos ahora con Alonso y con un Manuel que tiene intención de unirse al conflicto bélico dejando a su novia en un convento. La razón es simple: Juan Bautista mancilló el honor de la quinta causando

\footnotetext{
${ }^{12}$ Para la lectura ofrecida de Portugal en esta pieza, ver Grokenberger, 1988.
} 
un altercado; el portugués mató a un hombre, hirió a otro y provocó la huida del difamador. En Sanlúcar se halla también Luis, que goza ahora de rango de alférez, pero que sin embargo decide volver a Salvatierra acompañado de Manuel tras escuchar la historia de su amigo. Al enterarse a su retorno de que ha sido condenado a muerte, busca al juez de la sentencia, pone a sus criados de centinela a la puerta de la casa de este, se apodera de los autos y se escapa con sus servidores. La jornada final tendrá como escenario el monte, donde confluyen todos los personajes. Para limpiar su nombre se enfrenta asimismo al testigo que lo acusó - que no es otro que Juan Bautista, en condición de cristiano viejo - revelando su falsedad y dándole muerte. Luis es herido de un tiro de fusil y hecho prisionero, para ser liberado finalmente, terminando de este modo la comedia con la posibilidad de hacerse fraile una vez abandonada la «máscara» (p. 174) del bandidaje. La ausencia de una segunda parte que se promete en los últimos versos puede responder a un asunto concreto, como fue la Real Pragmática de Felipe IV (15 de junio de 1663) declarando proscritos a los bandoleros - y ratificada con algunas variantes por Felipe V el 23 de febrero de 1734-o quizá a dos cuestiones acaso más complejas: para Suárez Miramón se ha visto como una reacción de Calderón a la condena del casuismo del papa Alejandro VII en 1664, mientras que Margaret R. Greer ha conjeturado en el autor de La vida es sueño la imposibilidad de encontrar «a perfect individual balance between desire and the many faces of law» $»^{13}$. Estas múltiples caras de la ley, como bien han señalado Antonio Regalado y Henry Sullivan, implican que en el Derecho de la época era legítimo matar al falso testigo o falso acusador, y que la teología moral permitía matar incluso al juez, según sostenían los probabilistas: todo un complejo panorama teológico y legal detrás de una pieza relativamente sencilla ${ }^{14}$.

La ley, de hecho, juega en esta obra un papel medular. Laura Martín Murillo ha definido a Luis como «un hombre de acción» con un «exacerbado sentido del honor», «irrespetuoso e irreflexivo», que sigue «un código de conducta que no considera siquiera necesario explicar», destacando así por su altruismo, lealtad y fidelidad, mientras que Don

\footnotetext{
13 Greer, 2013, p. 651.

${ }^{14}$ Ver Regalado, 1995, I, p. 279; Sullivan, 2002, p. 243. Ver asimismo el apunte de Rodríguez Cuadros, 2004, p. 271.
} 
Cruickshank lo ha tachado de «unusual» $\mathrm{y}$ «strange». ${ }^{15}$ El motivo capital, que impulsa al protagonista a hacerse bandolero, es la rígida observancia de la ley del honor con arreglo a las ideas del momento. Cuando su reputación es puesta a prueba por partida doble - tras su crimen y tras el deshonor a su hermana-, el nombre de Luis aparece en pregones anunciando el embargo o pérdida de sus bienes, que son subastados a los campesinos locales. El gallego está atrapado en un círculo fatal, pues la posibilidad de un perdón monárquico, que le habría sido dado al servir en el ejército, queda eliminada al echarse al monte y tener que volver después a casa para restaurar su honra. Sin embargo, más allá de ser una historia de honor, amistad, valentía y lealtad, la pieza cuenta con una serie de detalles que justifican la aparición de otro conjunto de cuestiones mucho menos evidentes, pero de no menor relevancia. Calderón sitúa muy significativamente la acción en una comarca fronteriza, Salvatierra de Miño, en la raya meridional de la provincia de Pontevedra y separada de Portugal tan solo por el río. Tal emplazamiento conduce a una precariedad constante, a una transitoriedad que contrasta con la estabilidad doméstica anhelada por los hermanos en lo que Luis definirá como una «casa de placer». Se ofrecen, también, una serie de matizaciones que, a la larga, resultan de importancia capital: el protagonista mata al alguacil «a cuchilladas» en legítima defensa, y luego hace lo propio con el testigo de su caso por perjuro. Regalado y Suárez Miramón ${ }^{16}$ coinciden en señalar que tal resolución se permitía en el sistema legal de la época, pues no se estaba yendo en contra de la ley per se, sino de sus ejecutores. Luis, en este sentido, «ejecuta un nuevo orden», ya que "[E]l pesquisidor no indaga ni en las causas del delito ni en las circunstancias del mismo y ni siquiera comprueba el testimonio de los testigos» ${ }^{17}$. Este nuevo orden rebajará la reputación y credibilidad del juez hasta lo puramente trivial: cuando este pide dos mil escudos por su cabeza, el gallego le responde que le tasa muy bajo, y que él pedirá cuatro mil por la suya. Si bien la escena ocurre ya en el final de la pieza, el envite de Luis marca un antes y un después en el desarrollo de la trama, pues no solo anuncia ya que carecemos de una sola legalidad, sino también que el Estado no tiene

${ }^{15}$ Martín Murillo, 2002, pp. 242-243; Cruickshank, 2009, p. 105. Un análisis muy completo de los personajes en esta comedia se lleva a cabo por Pena Sueiro, 1996.

${ }^{16}$ Regalado, 1995, I, p. 279; Suárez Miramón, 2013, p. 215.

${ }^{17}$ Suárez Miramón, 2013, p. 216. 
jurisprudencia alguna si la representan funcionarios ineptos o corruptos. No en vano Luis afirmará que
Y si es que atento a lo escrito deben sentenciar los jueces no han de ser falsos testigos; que también los jueces deben escuchar en el descargo.
$[\ldots]$
No quiero amigos letrados; que no obligan a los jueces las palabras; que ellos hacen a propósito las leyes (p. 164).

Y acabará tomando el proceso él mismo, leyendo a Juan Bautista, a modo de juez justo, «lo que es verdad y mentira» (p. 172). La jerarquía social queda así disuelta al reactivarse nuevos parámetros legales emergentes de este espacio liminal que supone la raya galaico-portuguesa. Luis ha sido visto por Cruickshank como un "principled anarchist»" ${ }^{18}$ enfrentado a un poder injusto encarnado por agentes como los alguaciles, quienes para el calderonista británico "seem to have been universally unpopular, and were regularly complained about or satirised ${ }^{19}$. Yo diría, sin embargo, que su comportamiento responde de forma muy coherente a la de un arraiano que ha vivido tanto en Portugal — según nos recuerdan las palabras de Manuel cuando le pide ayuda - como en Galicia, y cuyo cruce de la frontera a nado y calado de río y niebla da cuenta de su condición vital y de su experiencia. Calderón, siempre atento a los detalles, se cuida mucho de matizar cómo ejecuta cada bando su legalidad, y cómo se acude a la violencia: las cuchilladas de Luis contrastan así con las balas de los alguaciles tanto como la virilidad corporal lo hace con la asepsia cobarde del disparo. Luis se comportará como un bandido honrado, recibiendo de los «villanos» del monte «solamente lo que dieren» (p. 165). E Isabel rechazará a Juan recordándole su condición de traidor y cobarde: «cuerpo a cuerpo, en desafio / fuera digno desagravio, / y de mis favores digno; / pero con la lengua no» (p. 160).

En este sentido, el paisaje y el sentimiento de pertenencia a la tierra resultan definitorios a lo largo de la pieza, siguiendo una línea argu-

${ }^{18}$ Cruickshank, 2009, p. 106.

${ }^{19}$ Cruickshank, 2009, p. 12. 
mentativa ya vista en otros dramaturgos contemporáneos. Si bien las silvas cantadas por Luis Pérez («Este monte eminente / cuyo arreglado ceño, cuya frente / es dórica columna» [p. 165]) recuerdan obligatoriamente a los vv. 14-16 de La vida es sueño («la aspereza enmarañada / de este monte eminente / que arruga al Sol el ceño de su frente»), lo cierto es que en este caso la imaginería escogida adquiere, al menos, dos connotaciones muy particulares: por una parte, la «dórica columna», ya utilizada con fines parejos por Calderón en los versos iniciales del auto sacramental El pastor Fido, y que simboliza la masculinidad majestuosa - podríamos decir que incluso ciclópea en su tamaño- de un ámbito inmisericorde que pondrá a prueba a los forajidos; por otra, la «eminencia» de un territorio ya legendario tanto desde el folklore como desde la esfera sociopolítica. Estamos, de hecho, ante una realidad histórica que nos remite a un fenómeno sumamente complejo, en la medida en que ya desde tiempos de Carlos $\mathrm{V}$ el bandidaje gallego había sido, según Manuel Fernández Álvarez, «endémico» ${ }^{20}$. La famosa Guerra Irmandiña (1466-1469) entre campesinos y comunidades urbanas y señores laicos del Reino había inaugurado varias décadas de tensión entre el gobierno central y determinados nobles gallegos que amparaban formas locales de bandidaje. La Santa Hermandad enviada por los Reyes Católicos, que habían visitado Galicia en 1486, no hizo mucho por mejorar las cosas, y el bandolerismo gallego continuó siendo, según indica la historiadora Allyson Poska, «always a threat» ${ }^{21}$. Es por ello que, leída en el contexto histórico galaico-lusitano que se recupera ahora, la pieza no es tan anómala ni sus personajes tan anárquicos. Esta es la Galicia, a fin de cuentas, de un contemporáneo como Pedro Fernández de Castro, séptimo conde de Lemos, protector de figuras como Zayas, Góngora, Lope, los Argensolas, Cervantes o Quevedo entre otros, y cuya familia provenía de uno de los focos más activos de bandidaje. Pero lo que aquí se recrea es la Galicia fronteriza de los arraianos, de aquellos súbditos imperiales enclavados en espacios rurales colindantes con Portugal y el norte de Castilla. Creo entonces que Calderón está capturando en este individuo de frontera un sentir paradójico con respecto a los gallegos, que desde el prisma madrileño de 1628 ofrecía una lectura elogiosa al tiempo que severa, con la pretendida pureza de espíritu exhibida por Luis y sus dos amigos como un arma de doble filo o, si se quiere, como

${ }^{20}$ Manuel Fernández Álvarez, 1979, p. 67.

${ }^{21}$ Poska, 2016, p. 40. 
un espacio en el que la línea entre lealtad y violencia quedaba peligrosamente difuminada.

Esta misma ambigüedad se cultiva con gran rendimiento teatral en estas primeras décadas del XVII: si bien es cierto que muchas comedias históricas que vuelven a tiempos medievales serán benévolas con Galicia - Lope de Vega había cantado a los «nobles campos de Galicia» en El mejor alcalde, el Rey y Tirso de Molina había hecho lo propio al hablar del "paraíso de Galicia» en La gallega Mari-Hernández-, más comunes y prosaicas van a ser las bromas y censuras. Incluso ciñéndonos a la propia comarca de Salvatierra, las letras áureas encumbran en estos años a una figura como Estebanillo González, natural de «Salvatierra de Miño", y que en su semblanza picaresca (La vida y hechos de Estebanillo González [1646]) aludirá al origen de cristiano nuevo de su madre y dos hermanas, definidas como «dos jarifas». La ausencia de pureza sanguínea venía ya arraigada en el imaginario popular y sería perpetuada desde el refranero con adagios despectivos como «antes moro que gallego", "antes puto que gallego» $\mathrm{o}$ «ni perro, ni negro, ni mozo gallego». ${ }^{22} \mathrm{Y}$ rasgos como la afición al vino, la dureza de sus paisajes rurales, la existencia de mujeres sumisas o la poca utilidad del idioma, como señaló Miguel Herrero García, acabarán por ser moneda común a la hora de definir esta región tan lejana y, al mismo tiempo, tan familiar para muchos. Recuérdese, por ejemplo, el paisano retratado en el célebre soneto de Góngora, "A Galicia» («traje tosco y estilo mal limado»), y que anuncia ya algo particularmente significativo en la comprensión de esta pieza en particular, a saber, la falta de sofisticación de muchos de sus habitantes, que al ser trasladados a las tablas daban lugar a paletos grotescos o a graciosos indiscretos, como había sido el caso en el propio Calderón con El astrólogo fingido, en donde el criado Morón era incapaz de guardar un secreto 23 .

El arraiano, sin embargo, se construye a partir de elementos dramáticos muy distintos. La porosidad que se escenifica en las diversas idas y venidas entre Salvatierra y Portugal responde a una realidad histórica que daba cuenta de una sólida confraternidad entre estos dos territorios - pertenecientes a un mismo monarca cuando se escribe la pieza- y que había sido ya señalada por más de un poeta: en La villana

${ }^{22}$ Correas, Vocabulario de refranes y frases proverbiales, p. 339.

${ }^{23}$ Un completo panorama del gallego en las letras áureas se ofrece en Teijeiro Fuentes, 1995. 
de la Sagra, por dar tan solo un caso, Tirso de Molina había puesto en boca del personaje Angélica que «el gallego acá en Castilla / dice que es de Portugal» (vv. 1351-1352), revelando un folklore compartido que será ahora ingrediente seminal en la historia de Luis Pérez, y dando cuenta así de la distancia abierta entre centro y periferia a la hora de definirse como vasallo de un mismo rey. El de Salvatierra se refugia en un Portugal recién anexionado a la Monarquía Hispánica (estamos en 1588), pero que para el momento en que Calderón estrena la pieza ha empezado a dar muestras ya de descontento debido a las exigencias fiscales y militares de la Corona, y que se manifestará muy pronto en las revueltas de 1634 y 1637 en el Alentejo. Este sentido de diferencia con respecto a la corte adquiere además un matiz muy particular en esta comedia, en donde se recupera además una circunstancia histórica en la figura del anti-héroe Juan Bautista. Al establecerse la Inquisición en Portugal, muchos conversos que habían huido volvieron a Galicia, repoblando lugares como Ribadavia, Monterrey, Orense, Monforte o Salvatierra $^{24}$. Luis y Elvira encarnan la Galicia legendaria que habían recuperado Lope y Tirso en sus nostálgicos retratos, mientras que Juan Bautista o Estebanillo González representarán el nuevo hibridismo resultante de los desplazamientos sufridos por comunidades perseguidas. La nobleza de carácter se contrastará en los teatros madrileños con la ética más que dudosa de conversos o moriscos, granjeándose Luis Pérez el favor de su audiencia tanto por lo que representa como por lo que repudia. Calderón cuenta así con todos los ingredientes necesarios para dramatizar una realidad no desconocida para su audiencia madrileña, en unas décadas de expansión urbana en las que, según ha señalado David Vassberg, un 20\% de la inmigración a la Villa procedía de Galicia ${ }^{25}$.

${ }^{24}$ Para una aproximación a la realidad histórica, ver, por ejemplo, Contreras, 1982, en especial pp. 23-25 y 43 para el problema judío en el sur de Galicia (con alusiones concretas al problema en Salvatierra en pp. 135 y 203); más recientemente, ver, por ejemplo, De Artaza, 1998. La amenaza de inestabilidad no era solo interna, como nos recuerda Contreras: «Galicia, zona Atlántica, es un enorme ventanal que es preciso cerrar a los aires contaminantes que venían de unos mares infectados de herejías hugonotes y anglicanas» (p. 17). Se unía a ello el hecho de que todavía a fines del XVI "Galicia es zona de clérigos analfabetos y de gente un tanto alejada de las prácticas ordinarias del culto católico», según Contreras (p. 47). La Inquisición no se estableció en Santiago hasta 1574.

${ }^{25}$ Vassberg, 1995, p. 155. Para un estudio sobre el estatus de la mujer en la Galicia del xviI, ver, por ejemplo, Poska, 2006. 
No cabe duda, por tanto, de que en este personaje se explota con gran habilidad el rendimiento teatral de la figura del bandido, dotándole de una lectura política muy conectada con su tiempo. El precio que el gallego pone a la cabeza de su juez invierte los términos de la dialéctica inocente-culpable, al tiempo que el rechazo a participar en la famosa expedición de 1588 con el fin de lavar el nombre propio subraya la urgencia de lo individual frente al deber del imperio o, incluso se podría decir, la meta concreta y razonable frente a la empresa quimérica cuyo fracaso es ya una página escrita en la historia de España cuando se estrena la pieza. Luis decide no enrolarse en la máquina imperial para, en última instancia, escoger la más radical de las periferias, la que le aboca a la raya galaico-portuguesa, a ese monte escarpado que es reducto de una serie de valores en peligro de extinción: Galicia se dramatiza como uno de los últimos bastiones de apego a la tierra frente a la corrupción del brazo judicial o la inmoralidad del vecino converso. El Pérez de Luis Pérez, la llaneza de su prosapia centenaria no contaminada, apunta aquí a la renuncia de la empresa colectiva en pos de la supervivencia del débil, representada en este caso no solo en su hermana, sino también en el Méndez y el Tardoya de sus dos amigos, de cuyo bienestar se hace responsable desde el inicio y sin reservas. Es quizá por ello que, en una de las escenas más dramáticas de la pieza, Luis transporta a Alonso a hombros al cruzar el río, asumiendo con ello la culpa de su amigo y, en cierta forma, haciéndola suya también, no solo desde el punto de vista legal (pues acoge a un fugitivo), sino también metafórico, en un gesto desinteresado que marcará de forma evidente su propio destino trágico.

\section{CALDERÓN, SÁTIRA Y MEMORIA}

La promesa de una segunda parte en los versos finales de Luis Pérez el gallego da cuenta de la confianza puesta por parte de Calderón en el rendimiento teatral de semejante dramatis persona. Si la figura del bandolero alcanza cotas de gran popularidad en los teatros del XVII, su presencia en la vida intelectual del siglo siguiente va a resultar, por el contrario, tan controvertida como el mismo género de la comedia nueva. Al igual que hará Roque Guinart con respecto a Cervantes, Luis Pérez va a emanciparse de Calderón para continuar un nuevo itinerario de reencarnaciones futuras, si bien desprovisto de muchos de sus rasgos primigenios. Esto no va a suponer, sin embargo, que la pieza descienda en popularidad, como demuestra la curiosa y extraña trayectoria de la que 
disfruta en los primeros compases del siglo XviII. Sabemos ya que desde la Fama, vida y escritos de Calderón de Juan de Vera y Tasis, publicada un año después de la muerte del dramaturgo, los elementos retóricos que operan en la canonización calderoniana se van a ir repitiendo de testimonio en testimonio, generando una inercia crítica no necesariamente rigurosa en sus planteamientos. Lo que el crítico John Guillory ha denominado «rituales de credencialización» ${ }^{26}$ se irá llevando a cabo de manera continuada a través de dos procesos fundamentales, como son los de influencias y oposiciones, construyéndose, poco a poco, una noción de valor que descansa en rasgos como el decoro y la verosimilitud, la fidelidad a los preceptos clásicos y la existencia o no de un término que va a repetirse continuamente en las reseñas teatrales, como es el de los desarreglos ${ }^{27}$. Y el bandido, con su conducta excesiva e impredecible y con una movilidad que fuerza al dramaturgo a emplazar la acción en múltiples lugares, encarna esa misma estridencia. No sorprende, por ejemplo, la ambivalencia de un Ignacio de Luzán, que en su Poética dirá de Calderón que «sirvió y sirve de modelo, y son sus comedias el caudal más redituable de nuestros teatros $»^{28}$, pero al mismo tiempo tacha a Luis Pérez el gallego de "escuela de crueldad», lamentando "tantos amoríos, pendencias y escondites", rechazando con ello los ingredientes que la habían canonizado en el Barroco.

Esto no va a significar, sin embargo, que el bandido calderoniano quede relegado al furgón de cola del imaginario dieciochesco, como demuestra una reencarnación de enorme interés en forma de epístolas satíricas que se intercambian a inicios de siglo un autor apócrifo y un Luis Pérez imaginario ${ }^{29}$. Nos encontramos ya ante un personaje que, si bien aparece ya emancipado de su ancestro calderoniano, no se ha desvinculado del todo. El formato de estas cartas es el de la redondilla, que se remata con un título de comedia áurea (El lindo don Diego, La hija del aire, Reinar después de morir...), a las que se añaden décimas dedicadas a un personaje del momento. En estas breves noticias, a modo de gaceta,

\footnotetext{
${ }^{26}$ Guillory, 1993. Sobre el fenómeno del canon literario y los avatares históricos que determinan el destino de una obra en concreto, ver Smith, 1988.

${ }^{27}$ Para el fenómeno de la recepción crítica del teatro áureo en los siglos XVIII y XIX, ver, por ejemplo, Checa Beltrán, 1993; Ganelin, 1994; García Santo-Tomás, 2000.

${ }^{28}$ Luzán, La Poética, p. 404.

${ }^{29}$ Las epístolas se catalogan en Fernández Valladares, 1988, pp. 211-213, 228-229. A modo de aproximación general sobre el papel de la prensa en el siglo xviII, siguen resultando de gran utilidad Castañón, 1973; Aguilar Piñal, 1978; y Sáiz, 1987.
} 
el bandido le informa a su amigo de la peligrosa situación en la que se encuentra el país tras la muerte de Carlos II en 1700, en un momento en el que la cuestión sucesoria se convertirá en un conflicto internacional con España como un atractivo botín para las diferentes potencias europeas. Estamos ya en plena Guerra de Sucesión, con sentimientos nacionalistas y centralistas a flor de piel debido a las pugnas entre borbónicos y austracistas, y la correspondencia con este bandido alejado de su origen sirve no solo para comentar los eventos del presente, sino también para meditar sobre la relevancia histórica del bandidaje gallego en un momento en el que la noción de lo español evoluciona hacia un incierto destino. Esta incertidumbre se va a agudizar a partir de 1704, cuando los enfrentamientos por el control de la Corona pasan a la Península y se desata la sátira periodística a través de relaciones y comentarios de índole propagandística adhiriéndose a la causa de Felipe V. Dotado de una ironía de la que carecía el modelo barroco, Luis Pérez va a servir ahora para resumir en tres epístolas los avatares de la Guerra recurriendo a ese mismo modelo del que se ha emancipado. Se comenta entonces la incorporación de Portugal a la causa aliada en 1703 y la coronación del Archiduque Carlos III, que llegó a Lisboa a inicios de 1704. En la frontera portuguesa se las habían visto con las tropas de Felipe V, como nos narran las redondillas, y durante la primavera se dieron las primeras batallas, que resultaron en las rendiciones de Mont-Santo, Castelo-Branco, Portalegre y de la patria del Luis barroco, Salvatierra. El bandido gallego toma la causa, siguiendo la adhesión de las clases populares, del nuevo monarca Borbón, denunciando a determinados nobles que habían alcanzado enormes privilegios y riqueza tras dos siglos de dominio de la casa de Austria, y que se habían pasado al bando portugués. En la tercera de las epístolas, Carta del amigo ausente a Luis Pérez el gallego (1704), este último le informa de dos deserciones como fueron las del Conde de Corzana y la muy sonada del Almirante de Castilla, que había salido de Madrid para ocupar su nuevo cargo como embajador en París, pero que cambió de rumbo y se exilió en Lisboa; desde allí publicó un manifiesto —que se critica por el bandido sin ambages — en el que acusó a Madrid de corrupto. Semejante traición le supuso al conocido diplomático la condición de proscrito y la confiscación de sus bienes, una suerte muy familiar a la del Luis barroco, que al reaparecer ahora en la historia literaria dará una visión diametralmente opuesta a la sufrida por él mismo casi un siglo antes, sirviendo de portavoz de los intereses del gobierno 
central que unas décadas antes había repudiado. Cuando le responde el amigo en una epístola de 1706 agradeciéndole las noticias, dedica sus primeros versos a elogiar el enorme ingenio del gallego:

Luis Pérez, ya que has dejado
de escribirme con tu frase,
no extrañarás, que yo pase
a seguir el comenzado.
Los títulos apuraste
en tus tres cartas discretas,
y tanto el concepto aprietas
que ninguno me dejaste.
Con los pocos que quedaron
esta te escribo, advirtiendo,
que de lo que no comprendo
el no ser más, le causaron.
Remítotelas hoy,
para cumplir lo que digo;
que esto es procurar, amigo,
Cada uno para sí.

Los versos sirven de preámbulo a la narrativa que a continuación resumirá la convulsa escena política de finales de 1705: el cerco de Barcelona a cargo del Archiduque y una expedición inglesa, las capitulaciones de Barcelona en octubre y de Valencia en diciembre, y el sitio de Badajoz llevado a cabo por Pedro de Portugal en octubre. La apropiación de la figura de Luis Pérez se ajusta a que Frank Kermode denominó, en su artículo homónimo, «el control institucional de la interpretación»; pero es este un control paradójico desde su misma configuración, en la medida en que el bandido se convierte ahora en portavoz del poder hegemónico aunque lo haga disfrazado de figura menor ante una poderosa invasión externa. Su nuevo papel de corresponsal constituye además un eslabón importante en la historia del canon teatral barroco y de la recepción crítica de Calderón en particular ${ }^{30}$, en la medida en que es su creación la que vuelve al centro mismo del debate político para narrar el presente desde códigos provenientes de la comedia nueva, homenajeando de paso a sus más excelsos poetas. Las redondillas nos ofrecerán, a fin de

\footnotetext{
${ }^{30}$ La bibliografía existente sobre este fenómeno es amplia; destaca, de entre lo publicado en los últimos años, Pérez Magallón, 2010; Manrique Gómez, 2011.
} 
cuentas, una selección de títulos que resultaban familiares al ciudadano del cambio de siglo, dando cuenta de un tipo de gusto muy concreto, con piezas como El ofensor de sí mismo (de Cristóbal de Monroy) o la moretiana Travesuras son valor, apenas conocidas o estudiadas hoy en día. Nos encontramos en un momento de transición en la historia literaria, con un Calderón que ha desaparecido hace más de un cuarto de siglo y sin una figura clara $-\mathrm{o}$ un quehacer teatral concreto- que lo haya destronado. Los versos demuestran, por tanto, que el lector de estos primeros compases del XviII participa de los códigos de la sátira poética al estar todavía muchas de estas piezas en el candelero. Cada estrofa ofrece, como resultado, una doble trayectoria: por una parte, la mirada al futuro que se avecina tras el reordenamiento geopolítico derivado de la guerra; por otra, el gesto nostálgico que, aunque revestido de humor, sugiere que los valores del teatro barroco son todavía relevantes, y que sus mismos títulos no resultan baladíes. Es esta, a fin de cuentas, «una literatura popular incorrecta, emocional hasta llegar al delirio, dominada por pasiones hondas y morbosas [...], en la que quedará una de las manifestaciones más palpables de la prolongación del Barroco literario» ${ }^{31}$.

\section{CALderón, historia y Biopolítica}

Los contenidos de este intercambio epistolar, así como la retórica de la que participan, constituyen uno de los primeros ejemplos de lo que será un largo proceder hermenéutico de más de doscientos años, sometiendo al bandido regional a continuas transformaciones y recreándolo desde diversos códigos, hasta llegar a determinados iconos de la cultura popular del siglo $\mathrm{xx}$ que reescriben todo un conjunto de nociones capitales asociadas a debates críticos en torno a espacio, género y memoria local ${ }^{32}$. He indicado ya que el bandido de esta diacronía que había popularizado Calderón no solo es gallego, es arraiano y, como tal, alguien que, según se ha escrito en el contexto del diecinueve, «piensa Galicia no desde las historias nacionales o desde las tradiciones culturales, sino desde sus fronteras, y desde las múltiples posiciones históricas y culturales de sus habitantes espectrales» ${ }^{33}$. La palabra clave aquí es, manteniendo su sentido derridiano, espectral. En tono burlesco y desde

${ }^{31}$ Fernández Valladares, 1988, p. 15.

${ }^{32}$ Ver, por ejemplo, Palacios, 1993, y el excelente recorrido de Le Guin, 2014, a través de diferentes manifestaciones artísticas.

${ }^{33}$ Moreiras-Menor, 2003, p. 208. 
la periferia Luis Pérez informa de asuntos urgentes a través de ejemplos extraídos del pasado, manteniendo así viva la presencia de este arquetipo hasta que coge el relevo Manuel de Anero Puente con la siguiente de las reencarnaciones. La Galicia del forajido pervive así en el tiempo como un espacio desde el que articular importantes debates en torno al alcance del poder central y la autonomía del súbdito considerado como periférico, con esta "segunda parte» homónima situada a medio camino entre estos dos momentos históricos tan determinantes para el bandidaje como fueron, según he indicado ya, la Guerra de Sucesión y la Guerra de la Independencia. Así va a ocurrir en el segundo de estos conflictos, cuando las tropas de Napoleón se encontraron en Galicia con problemas de alojamiento y abastecimiento. Al tiempo que el ejército francés iba ocupando el territorio, el bandolerismo gallego se organizó en gavillas que operaban con violencia y que, a diferencia de las andaluzas o extremeñas, no eran permanentes. La queja principal que los militares franceses tenían acerca de la guerra en Galicia era la de no poder acorralar al enemigo, y cuando esto ocurría de no poderlo destruir, porque se dispersaba y se volvía a reunir algún tiempo después en otro punto, moviéndose por las montañas de Galicia, León, Asturias y frontera portuguesa, sorprendiendo a sus enemigos con audaces emboscadas. Sin embargo, una vez terminado el conflicto y sin la amenaza de un enemigo externo tan evidente, el bandido gallego fue repudiado por el pueblo, dado que más de la mitad de los robos fueron en iglesias y contra familias campesinas de escasos medios, y debido también a la práctica común de torturar a muchas de sus víctimas.

Beatriz López Morán ha defendido la hipótesis de que el bandolerismo en Galicia fue una actividad de subsistencia en una sociedad rural, sin un tirón industrial y con una economía a la baja, en la cual habían desaparecido los mecanismos asistenciales de la Iglesia tras la Desamortización. A pesar de sus múltiples robos y de la espectacularidad de sus acciones, las gavillas pudieron operar con bastante comodidad en la zona durante algún tiempo, gracias a la escasez y a la inoperancia de las fuerzas judiciales y policiales, así como a la inestabilidad provocada por la primera Guerra Civil (1821-1823), las Guerras Carlistas (1834-1841, 1847) y los Levantamientos de 1840,1843 y 1846 . Al igual que ocurría en otras partes de Galicia, los jueces no se mostraban muy beligerantes contra estos delincuentes, seguramente porque ellos mismos no se consideraban bien protegidos, como ocurría, por ejemplo, en la comarca 
ya citada de Monforte. En la década de los veinte había sido nombrado capitán general de Galicia el célebre militar Nazario Eguía, quien puso especial empeño en restablecer el orden en las áreas más afectadas por la delincuencia, sin preocuparse mucho por las formalidades jurídicas. Bajo su mandato empezaron a emitirse sentencias más duras, incluyendo las de muerte, con lo que la actividad criminal decayó notablemente. Pero incluso cuando los bandidos eran detenidos y juzgados, las sentencias solían ser excesivamente benignas, aunque se hubiesen cometido toda clase de brutalidades. No sorprende que la propia figura de Manuel Murguía, padre del nacionalismo gallego y líder del movimiento regionalista, tratara de forma indirecta el contexto histórico del bandidaje en su famoso estudio De las guerras de Galicia en el siglo XV y de su verdadero carácter (1861). Se cumplían ya casi cien años de intervencionismo institucional en los que ni el ejército (desde 1781), ni los Voluntarios realistas (desde 1823), ni el Cuerpo de Carabineros (desde 1829) ni la Guardia Civil (desde 1844) fueron capaces de eliminar el fenómeno que dio lugar a figuras legendarias como la del propio Luis Pérez.

El teatro se constituye, por tanto, como uno de los medios principales con los que divulgar una determinada imagen del bandolero periférico, tal y como indicaba al inicio de este ensayo con ese Roque que, al igual que Luis Pérez ahora, se distancia de su origen y se instrumentaliza para construir una determinada imagen del país. Esta apropiación del arquetipo se ajusta a una de las acepciones más clásicas de biopolítica, entendida aquí como el conjunto de saberes, técnicas y tecnologías que convierten la capacidad biológica de los seres humanos en el medio por el cual durante el siglo XVII el Estado alcanza sus objetivos. ${ }^{34}$ No es por tanto arriesgado afirmar, en suma, que la Galicia calderoniana ha seguido existiendo, con mayor o menor fortuna a lo largo del tiempo, como un arquetipo social invocado en momentos de crisis, como ese espectro que reaparece una y otra vez. Ya casi en los albores del siglo xx, el periódico El Faro de Vigo, en su tirada del 11 de enero de 1887, daba noticia de un personaje de Salvatierra de Miño que capitaneaba un grupo de bandidos dedicados a pillaje.Y un periódico de Valenza del Miño recogería poco más tarde la muerte de un balazo del bandido Manuel Antonio Núñez, 'el Crico', natural de Salvatierra, cuyos compinches escaparon momentáneamente huyendo a Portugal. La historia vuelve a repetirse en el conflicto, ya clásico, del individuo frente a la ley,

${ }^{34}$ Foucault, 1999, p. 245. 
de la comarca de Salvatierra que se abandona en busca, una vez más, del desconocido futuro portugués. Una comarca y unos bandidos, cabe recordar, que volverán a estar presentes en el imaginario popular gracias al famoso diario de viaje del inglés George Borrow titulado La Biblia en España, traducido por Manuel Azaña en 1912 y reimpreso después en 1921, en 1956 (en traducción de Elena García Ortiz) y 1967. Pero lo que resulta más sobresaliente es que, en un momento histórico como el presente en el cual se sigue representando Luis Pérez el gallego en los teatros de Galicia ${ }^{35}$ y vuelve a ser recuperada en formato visual la figura del arraiano $^{36}$, la impronta de ese Calderón profundo, cómico y doctrinal es también la de un Calderón preocupado por llevar a las tablas el sentido de diferencia interna de un imperio plural que busca su propia identidad. Luis Pérez viene a situarse así en los intersticios de eso que se ha venido a llamar recientemente "regionalismo crítico», de ese

intento de recuperar y poner de manifiesto la complejidad de los niveles de la historia cultural no con el propósito de promover, una vez más, la integración activa de la región en una forma más amplia nacional o transnacional, sino con el muy diferente de pensar los lugares de especificidad y diferencia que se encuentran en los residuos y sedimentos producidos y dejados atrás por las historias de dominación ${ }^{37}$.

La presencia de este 'teatro de frontera' revela que estas historias de sus héroes populares son también historias de hegemonía, con la maceración de Luis Pérez como resultado tanto de su iconicidad local como de la necesidad de ser poseído - e igualmente manipulado- desde un discurso dominante, sea cual sea el momento histórico en el que se construya.

${ }^{35}$ Ver, por ejemplo, la versión de 2000 a cargo Juan Udaondo Alegre con la compañía de teatro Farsalia.

${ }^{36}$ Ver Enciso, 2002, que a su vez recupera la importancia histórica de otro texto (siguiendo esta línea argumentativa) espectral, O Bosque, de Jenaro Marinhas del Valle.

${ }^{37}$ Moreiras-Menor, 2003, p. 208. 


\section{Bibliografía}

Aguilar Piñal, Francisco, La prensa española en el siglo XVIII. Diarios, revistas y pronósticos, Madrid, Consejo Superior de Investigaciones Científicas, 1978.

AnDioc, René y Mireille Coulon, Cartelera teatral madrileña del siglo XVIII (17081808), Toulouse, Presses Universitaires du Mirail, 1996, 2 vols.

Anero Puente, Manuel de, Luis Pérez el gallego. Comedia nueva. Segunda parte, Sevilla, Francisco de Leefdael, 1717.

Anónimo, Carta del amigo ausente a Luis Pérez el gallego, en que le noticia los sucesos que al presente se miran en Cataluña, Valencia, y Portugal, continuando el comenzado idioma de títulos de comedias (en que le escribía) y apurando el asunto de ellos, Madrid, s.1, 1706.

Antonucci, Fausta, El salvaje en la comedia del Siglo de Oro. Historia de un tema de Lope a Calderón, Pamplona, Toulouse, Universidad de Navarra (RILCE), Université de Toulouse (LESO), 1995.

Arellano, Ignacio, «Espacios dramáticos en los dramas de Calderón», en Calderón: sistema dramático y técnicas escénicas. Actas de las XXIII Jornadas de Teatro Clásico, Almagro, ed. Felipe B. Pedraza Jiménez, Rafael González Cañal y Elena Marcello, Cuenca, Universidad de Castilla-La Mancha, Festival de Almagro, 2001, pp. 77-106.

Bergman, Ted L. L., The Art of Humour in the Teatro Breve and Comedias of Calderón de la Barca, Woodbridge, Tamesis, 2003.

Buezo, Catalina, «Luis Pérez el gallego de Pedro Calderón de la Barca: cuestiones de género en una pieza temprana», El Siglo de Oro en escena. Homenaje a Marc Vitse, ed. Odette Gorsse y Frédéric Serralta, Toulouse, PUM (Anejos de Criticón, 17) / Consejería de Educación de la Embajada de España en Francia, 2006, pp. 123-132.

Calderón de la Barca, Pedro, Luis Pérez el gallego, en Obras Completas, vol. I, Ángel Valbuena Briones, ed., Madrid, Aguilar, 1969.

Cardinale, Rosa, El bandolero español entre la leyenda y la vida real. Calas en configuraciones del bandolero en textos paradigmáticos de los siglos XVII-XX, Madrid, Verbum, 2009.

CASTAÑón, Jesús, La crítica literaria en la prensa española del siglo XVIII (1700-1750), Madrid, Taurus, 1973.

Checa Beltrán, Jorge, «Los clásicos en la preceptiva dramática del siglo XVIII», Cuadernos de teatro clásico. Clásicos después de los clásicos 5, 1990, pp. 13-31.

Coello y Pacheco, Carlos, Roque Guinart, Madrid, Imprenta de la Biblioteca de Instrucción y Recreo, 1874.

Contreras, Jaime, El Santo Oficio de la Inquisición en Galicia, 1560-1700. Poder, sociedad y cultura, Madrid, Akal, 1982. 
Correas, Gonzalo, Vocabulario de refranes y frases proverbiales $y$ otras fórmulas comunes de la lengua castellana, Madrid, Tipología de la Revista de Archivos, Bibliotecas y Museos, 1924.

Cruickshank, Don, Don Pedro Calderón, Cambridge, Cambridge University Press, 2009.

De Artaza, Manuel María Rey, reino y representación. La Junta General del Reino de Galicia (1599-1834), Madrid, Consejo Superior de Investigaciones Científicas, 1998.

Enciso Cachafeiro, Ernesto, Arraianos, Ártika Films, 2013.

Fernández Álvarez, Manuel, España y los españoles en tiempos modernos, Salamanca, Universidad de Salamanca, 1979.

Fernández Valladares, Mercedes, Catálogo bibliográfico y estudio literario de la sátira política popular madrileña (1690-1788), Madrid, Universidad Complutense, 1988.

Foucault, Michel, Estética, ética y hermenéutica, ed. Ángel Gabilondo, Barcelona, Paidós, 1999.

Ganelin, Charles, Rewriting Theater. The 'Comedia' and the Nineteenth-Century Refundición, Lewisburg, Bucknell University Press, 1994.

GARCía CÁrCEL, Ricardo, «El bandolerismo catalán en el siglo XVII», en El bandolero y su imagen en el Siglo de Oro. Le bandit et son image au Siècle d'Or, ed. Juan A. Martínez Comeche, Madrid / Paris, Casa deVelázquez / Université Paris-Sorbonne / Edad de Oro / Universidad Internacional Menéndez Pelayo, 1989, pp. 43-54.

García González, Antonio, «El bandolero histórico como personaje de comedia en Lope», Anuario Lope de Vega, 18, 2012, pp. 63-79.

García Santo-Tomás, Enrique, «Recasting Roque: Cervantes's Bandits and the Politics of Drama», Modern Language Review, 112, 1, 2017, pp. 156-172.

García SANTO-Tomás, Enrique, La creación del 'Fénix': recepción crítica y formación canónica del teatro de Lope de Vega, Madrid, Gredos, 2000.

Greer, Margaret R., "The Weight of Law in Calderón», Bulletin of Spanish Studies, 90, 4-5, 2013, pp. 651-678.

Grokenberger, Dorothée, "Calderón y Portugal (Luis Pérez, el gallego)», en Hacia Calderón, ed. Hans Flasche, Stuttgart, Franz Steiner, 1988, pp. 202-206.

Guillory, John, Cultural Capital. The Problem of Literary Canon Formation, Chicago, The University of Chicago Press, 1993.

Herrero García, Manuel, Ideas de los españoles del siglo XVII, Madrid, Gredos, 1966.

Hobsbawm, Eric, Bandits, New York, The New Press, 2000 [1969].

Jauralde Pou, Pablo, «El bandido en el teatro de Tirso de Molina», en El bandolero y su imagen en el Siglo de Oro. Le bandit et son image au Siècle d'Or, ed. Juan Antonio Martínez Comeche, Madrid, Anejo de Edad de Oro / Travaux du 
«Centre de Recherche sur l'Espagne des Xvi et XvII ${ }^{\mathrm{e}}$ siècles» / Casa de Velázquez, 1991, vol. IV, pp. 44-56.

Kermode, Frank, "El control institucional de la interpretación», en El canon literario, ed. y comp. Enric Sullá, Madrid, Arco/Libros, 1998, pp. 91-112.

Ledroit, Mathias, «Le stéréotype du bandit catalan dans la littérature espagnole du Siècle d'Or», Cahiers de Narratologie, 17, 2009, pp. 2-11.

Le Guin, Elisabeth, The Tonadilla in Performance. Lyric Comedy in Enlightenment Spain, Berkeley, University of California Press, 2014.

López Díaz, Carlos, «Los Roque Guinart de CDC», Actuall, October 27, 2015. Disponible en línea: <http://www.actuall.com/criterios/democracia/losroque-guinart-de-cdc $>$ [27/10/2016].

López Morán, Beatriz, El bandolerismo gallego en la primera mitad del siglo XIX, La Coruña, Ediciós do Castro, 1995.

LuzÁn, Ignacio de, La poética: o, Reglas de la poesía en general, y de sus principales especies, ed. Russell Sebold, Barcelona, Labor, 1977.

Manrique Gómez, Marta, La recepción de Calderón en el siglo XIX, Madrid / Frankfurt, Iberoamericana / Vervuert, 2011.

Martín Murillo, Luis, «Luis Pérez», Diccionario de personajes de Calderón, coor. Javier Huerta y Héctor Urzáiz, Madrid, Pliegos, 2002, pp. 342-343.

Moreiras-Menor, Cristina, «Regionalismo crítico y la reevaluación de la tradición en la España contemporánea», Arizona Journal of Hispanic Cultural Studies, 7, 2003, pp. 197-202.

Murguía, Manuel, De las guerras de Galicia en el siglo XV y de su verdadero carácter, La Coruña, Imprenta de E. Carré, 1861.

Palacios, Emilio, "Guapos y bandoleros en el teatro del siglo xviII: los temas y las formas de un género tradicional», Cuadernos para la Investigación de la Literatura Hispánica, 18, 1993, pp. 253-290.

PARKer, Alexander, "Santos y bandoleros en el teatro español del Siglo de Oro», Arbor, 13, 1949, pp. 395-416.

Pena Sueiro, Nieves, "Acerca de los personajes en Luis Pérez el gallego», Lenguaje $y$ textos, 8, 1996, pp. 93-108.

Pérez Magallón, Jesús, Cervantes, monumento de la nación: problemas de identidad y cultura, Madrid, Cátedra, 2015.

Pérez Magallón, Jesús, Calderón. Icono cultural e identitario del conservadurismo político, Madrid, Cátedra, 2010.

Poska, Allyson M., Gendered Crossings:Women and Migration in the Spanish Empire, Alburquerque, University of New Mexico Press, 2016.

Poska, Allyson M., Women and Authority in Early Modern Spain. The Peasants of Galicia, Oxford, Oxford University Press, 2005.

Regalado, Antonio, Calderón. Los orígenes de la modernidad en la España del Siglo de Oro, Barcelona, Destino, 1995, 2 vols. 
Reglá, Juan, «El bandolerismo en la Cataluña del Barroco», Anuario de Historia Económica y Social, I, 1968, pp. 281-294.

Rodríguez Cuadros, Evangelina, «Pedro Calderón de la Barca», The Cambridge History of Spanish Literature, ed. David T. Gies, Cambridge, Cambridge University Press, 2004, pp. 265-282.

Sárz, M. ${ }^{a}$ Dolores, Historia del periodismo en España. El siglo xVIII, Madrid, Alianza, 1987.

SALAs, Carlos, «Por qué el Quijote se le atraganta a algunos catetos en Cataluña», Lainformación.com, 21 de septiembre de 2015. Disponible en: <http:// blogs.lainformacion.com/zoomboomcrash/2015/09/25/por-que-el-quijote-se-le-atraganta-a-algunos-catetos-en-cataluna/> [27/10/2016].

Sмітн, Barbara H., Contingencies of Value, Cambridge, Harvard University Press, 1988.

SuÁrez Miramón, Ana, "Rebeldía y violencia en Luis Pérez el gallego», en

Violencia en escena y escenas de violencia en el Siglo de Oro, ed. Ignacio Arellano y Juan Antonio Martínez Berbel, New York, IDEA, 2013, pp. 209-222.

Sullivan, Henry, "Probabilismo», en Diccionario de la comedia del Siglo de Oro, ed. Frank P. Casa, Luciano García Lorenzo y Germán Vega García Luengos, Madrid, Castalia, 2002, pp. 242-243.

Teijeiro Fuentes, Miguel Ángel, «Galicia y los gallegos en la literatura española del Siglo de Oro", Scriptura 11, 1996, pp. 203-246.

Vassberg, David E., The Village and the Outside World in Golden Age Castile. Mobility and Migration in Everyday Rural Life, Cambridge, Cambridge University Press, 1996. 